\title{
Analyses of Lettuce Drop Incidence and Population Structure of Sclerotinia sclerotiorum and $S$. minor
}

\author{
B. M. Wu and K. V. Subbarao
}

Department of Plant Pathology, University of California-Davis, 1636 East Alisal Street, Salinas 93905.

Accepted for publication 4 July 2006.

\begin{abstract}
Wu, B. M., and Subbarao, K. V. 2006. Analyses of lettuce drop incidence and population structure of Sclerotinia sclerotiorum and S. minor. Phytopathology 96:1322-1329.

To understand the geographical distribution of lettuce drop incidence and the structure of Sclerotinia minor and S. sclerotiorum populations, commercial lettuce fields were surveyed in the Salinas, San Joaquin, and Santa Maria Valleys in California. Lettuce drop incidence, pathogen species, and mycelial compatibility groups (MCGs) were determined and analyzed using geostatistic and geographical information system tools. Lettuce drop incidence was lowest in the San Joaquin Valley, and not significantly different between the other two valleys. Semivariogram analysis revealed that lettuce drop incidence was not spatially correlated between different fields in the Salinas Valley, suggesting negligible fieldto-field spread or influence of inoculum in one field on other fields. Lettuce drop incidence was significantly lower in fields with a surface drip system than in fields with furrow or sprinkler irrigation systems, suggest-

the prevalent species, causing drop in $63.5 \%$ of the fields, whereas $S$. minor also was identified in $25.4 \%$ of the fields. In contrast, in the Salinas Valley, S. minor was the dominant species $(76.1 \%)$ whereas $S$ sclerotiorum only observed in only $13.6 \%$ fields, in which only a few plants were infected by S. sclerotiorum. In the Santa Maria Valley, both species frequently were identified, with $S$. minor being slightly more common. Although many MCGs were identified in $S$. minor, most of them consisted of only one or two isolates. In all, $\approx 91.4 \%$ of the isolates belonged to four MCGs. Among them, MCG-1 was the most prevalent group in all three valleys, accounting for $49.8 \%$ of total isolates. It was distributed all over the surveyed areas, whereas other MCGs were distributed more or less locally. Populations of $S$. sclerotiorum exhibited greater diversity, with 89 isolates collected from the Salinas and San Joaquin Valleys belonging to 37 different MCGs. Among them, the most recurrent MCG-A contained 16 isolates, and 30 MCGs contained only 1 isolate each. Many MCGs occurred within only one or a part of the two valleys. Potential reasons for this abundant diversity are discussed.
\end{abstract} ing that the surface drip system can be a potential management measure for reducing lettuce drop. In the San Joaquin Valley, S. sclerotiorum was

Lettuce drop, caused by Sclerotinia minor Jagger and S. sclerotiorum (Lib.) de Bary, is one of the most widespread and destructive diseases worldwide in lettuce production $(28,31)$. The United States is ranked number two in the world for both total production and export of lettuce Annual production increased from 4.35 to 4.98 million tons while export increased from 299 to 440 thousand tons during 1997 to 2004 (available online from the Food and Agriculture Organization of United Nations). Lettuce production in the United States was concentrated in California and Arizona. The two states accounted for 67 to $76 \%$ and 23 to $30 \%$, respectively, of the total U.S. lettuce production, which was valued at $\$ 1.43$ to 2.35 billion during 1997 to 2004 (available online from the U.S. Department of Agriculture, National Agricultural Statistics). Lettuce drop is one of the most important diseases in all the lettuce production areas in California and Arizona, causing severe yield loss annually $(27,28,31)$. Both $S$. minor and $S$. sclerotiorum survive mainly as sclerotia in soil. S. minor primarily infects lettuce by direct eruptive germination of soilborne sclerotia, and carpogenic germination of $S$. minor rarely has been observed in nature $(1,27)$. Large numbers of sclerotia are produced on colonized lettuce tissues and released into the soil to serve as inoculum for succeeding lettuce crops $(1,27)$. S. sclerotiorum also infects lettuce plants infrequently by direct germination of sclerotia; however, airborne ascospores from carpogenic germination of sclerotia are the primary inoculum source $(1,27)$.

Corresponding author: K. V. Subbarao; E-mail address: kvsubbarao@ucdavis.edu

DOI: $10.1094 /$ PHYTO-96-1322

(C) 2006 The American Phytopathological Society
Additional keywords: GIS, Lactuca sativa.
Occurrence of lettuce drop caused by S. minor is more consistent, whereas that caused by $S$. sclerotiorum is sporadic and associated with prolonged wet periods (4). Incidence of lettuce drop caused by $S$. minor is highly correlated with the number of soilborne sclerotia, whereas lettuce drop caused by $S$. sclerotiorum is not $(2,8,16,27)$.

Irrigation is the most important factor affecting epidemics of lettuce drop. Several different irrigation systems currently are employed in lettuce production in coastal California. Even though sprinkler irrigation offers many advantages over furrow irrigation for lettuce production (5), a large volume of soil becomes saturated under both systems, facilitating germination of sclerotia and infection of lettuce (32). Subsurface drip irrigation can significantly reduce soil moisture and, therefore, lettuce drop (32, 35). However, a surface drip system rather than subsurface drip is now employed widely in commercial production because of the high costs of maintenance over multiple seasons or replacement of subsurface drip system. It is unclear how lettuce drop incidence is affected by surface drip irrigation.

Of the major types of cultivated lettuce (crisphead, romaine, butterhead, and leaf lettuce), crisphead and romaine together compose $90 \%$ of all lettuce grown in the United States (29). Whether resistance to lettuce drop differs among different lettuce types is not known. Infection of lettuce by either species of Sclerotinia can occur at any growth stage, but infections caused by ascospores of $S$. sclerotiorum occur most often close to harvest maturity. There is evidence of age-related resistance to $S$. minor in broccoli (unpublished data); however, it is unclear whether susceptibility of lettuce to infection by either Sclerotinia spp. also changes over lettuce growth stages. 
The epidemiological differences between the two Sclerotinia spp. might be expected to affect their geographical distribution, in relation to climate and cultivation practices; however, how this relates to the geographical patterns of lettuce drop incidence is unknown. Furthermore, because of the need for different management strategies for the two species, quantitative studies on the geographical distribution of the two species will help develop effective management strategies for lettuce drop. The three major lettuce production areas in central California (Salinas Valley, Santa Maria Valley, and San Joaquin Valley) provide an interesting case study for examining the spatial distribution of lettuce drop and its causal pathogens. First, the species of Sclerotinia causing lettuce drop differ among the three valleys. S. minor and $S$. sclerotiorum are the predominant species in the Salinas and San Joaquin Valleys, respectively, but both species regularly cause lettuce drop in the Santa Maria Valley (27). Second, the valleys have very different climates and vegetable production systems. In the Salinas Valley, weather is generally cool, and lettuce can be grown year round except for a lettuce-free period between 7 and 21 December enforced by the county's regulation to manage Lettuce mosaic virus (31). In some fields, two lettuce crops are produced each year from the spring through summer to late fall (27). From north to south along the Salinas Valley, temperature generally increases as marine fog becomes less frequent (39). Accordingly, lettuce is planted earlier in the spring at the southern end of the valley and moves north subsequently. By contrast, in the San Joaquin Valley, temperature usually is too high for lettuce production during the summer. Lettuce usually is grown in the spring and fall when prolonged rainy and foggy weather keeps topsoil near saturation, allowing production of apothecia by $S$. sclerotiorum $(27,29)$. In the Santa Maria Valley, the weather is typically foggy, and lettuce is grown year round without a lettucefree period.

Vegetative incompatibility, the inability of two strains to fuse and form a stable heterokaryon, has been widely used in population genetic studies of fungi as an effective means of identifying intraspecific variation in populations (21). Because auxotrophic mutants are difficult to obtain for fungi in the genus Sclerotinia, mycelial incompatibility has been used in population studies of Sclerotinia spp. for categorizing intraspecific heterogeneity $(3,6$, $7,9,10,18-23,26)$. Mycelial incompatibility is believed to be associated with, but distinct from, vegetative incompatibility (10). Isolates of $S$. minor and $S$. sclerotiorum consistently are selfcompatible in mycelial compatibility groups (MCGs). Genetic heterogeneity characterized by MCG exists among isolates of $S$. sclerotiorum from a variety of hosts and geographical areas, even within a local field population $(3,18,26)$. Genetic exchange and recombination is occasional in $S$. sclerotiorum populations from canola (17), cabbage (7), and soybean (22). However, populations of $S$. sclerotiorum on infected potato not only exhibited high diversity but also demonstrated the potential for sexual recombination, with different MCGs identified from ascospores from one apothecium (3). Multiple MCGs also were identified in a population of $S$. minor on lettuce from diverse geographic locations (26) and from Ontario, Canada (23).

Soybean isolates of $S$. sclerotiorum from various geographical locations differed in aggressiveness, and variation in aggressiveness was high even within a single MCG (22). Difference in aggressiveness has not been studied for either pathogen species in the three lettuce-production areas, and no information is available on the interaction between pathogen isolates and host cultivars. Characterization of the geographical intraspecific diversity within $S$. minor and S. sclerotiorum populations is needed urgently for breeding of lettuce cultivars with stable resistance against lettuce drop.

Therefore, our objectives were to analyze the spatial distribution of lettuce drop incidence and the affecting factors, and to compare the geographical distribution of the two Sclerotinia spp. and their intraspecific (MCG) variations in the three major production areas in central California. A preliminary report of this research has been published previously (33).

\section{MATERIALS AND METHODS}

Field surveys. From fall 1999 to summer 2001, 4600 lettuce fields were surveyed in the three lettuce-production valleys in California. Specifically, 360 fields in the Salinas Valley (109 in October 1999 and 251 in late April to mid-May 2000), 63 fields in the San Joaquin Valley (11 in October 1999 and 2000 and 52 from mid-March to early April 2000 and 2001), and 37 fields in the Santa Maria Valley (on 30 March 2000 and 15 August 2001) were evaluated. Longitude and latitude was measured for each surveyed field using Global Positioning System Units (Model GPS 315; Magellan Corporation, San Dimas, CA). To determine incidence (percentage of lettuce plants infected by S. minor or S. sclerotiorum) in each field, 100 lettuce plants first were evaluated for drop. Starting from at least $10 \mathrm{~m}$ from any edge, 10 plants on one bed were examined at each stop diagonally crossing the field at intervals of $10 \mathrm{~m}$ along and across the rows. If no diseased plant was found among the 100 plants, 900 more plants were evaluated for a total of 1,000 plants (50 plants each at intervals of 5 by $5 \mathrm{~m}$ along the other diagonal line) and, if still no diseased plant was observed, then 1,000 more plants on five randomly selected $1-\mathrm{m}$ beds or two randomly selected 2-m beds (in total, 2,000 lettuce plants) were evaluated. Of the 460 fields surveyed, incidence of lettuce drop was determined for only 420 fields. The species of the pathogen causing lettuce drop in each field was determined tentatively in the field based on the size of sclerotia observed on diseased plants and, with one exception, was further confirmed by culturing the pathogen on potato dextrose agar (PDA) plates in the laboratory. The exception was one field in the Santa Maria Valley, in which the species of the pathogen could not be determined because sclerotia were not observed in the field and the subsequent isolation of the pathogen in the laboratory also was unsuccessful. Each lettuce field was classified into one of four categories: those containing only $S$. sclerotiorum, only $S$. minor, both species, and neither species. Type of lettuce (crisphead, leaf, romaine, and butterhead), growth stage of lettuce plants, and irrigation type also were recorded for each field. Whenever available, up to a few hundred sclerotia from 1 to 20 plants of both Sclerotinia spp., depending on availability, were collected from each field.

Grouping isolates based on mycelial compatibility. This study focused on the spatial distribution across different lettuce production areas instead of distribution within individual fields; therefore, only one sample (with a few exceptions) from each field was tested for mycelial compatibility. One to six sclerotia, depending on total number of sclerotia available, were taken randomly from the original sclerotia of S. sclerotiorum, S. minor, or both collected from each field and placed on a PDA plate. From each PDA plate, a 3-mm-diameter culture plug was transferred into a new PDA plate, except when $\geq 2$ colonies showed a demarcating line between them; in which case, all of them were transferred separately. Sclerotia formed on the new PDA plate and subsequent cultures were collected and stored for further tests. After confirming the species of collected sclerotia, the MCG of each isolate within each species was determined by pairing isolates on PDA amended with five drops $(0.25 \mathrm{ml})$ of McCormack's red food coloring per liter (20). A 3-mm-diameter plug of 3-dayold PDA culture from each of three isolates was placed within the same petri dish and arranged as an equilateral triangle $(\approx 4 \mathrm{~cm}$ from each other). After incubation at $20^{\circ} \mathrm{C}$ for 7 days, the reaction between each isolate pair was evaluated. If two isolates could grow together without any obvious line between them, they were considered compatible with each other. Otherwise, if a line formed between them, they were considered incompatible. In all, 243 
isolates of $S$. minor from the three valleys and 89 isolates of $S$. sclerotiorum from the Salinas and San Joaquin Valleys were grouped. Isolates of S. sclerotiorum from the Santa Maria Valley were excluded because very few isolates were available.

Data analysis. Means of lettuce drop incidence first were compared among the three valleys using pairwise $t$ tests. Then, in the Salinas Valley, lettuce drop incidence was compared further among fields using different irrigation systems (furrow, sprinkler, and surface drip), among fields infested by different species of pathogen ( $S$. minor alone, $S$. sclerotiorum alone, and both species), and among fields with different types of lettuce (leaf, romaine, and crisphead). These were done separately using pairwise $t$ tests. When irrigation types were compared, fields in which irrigation systems could not be determined were excluded from the analysis. Fields without any of the two species and fields with lettuce other than leaf, romaine, or crisphead lettuce also were excluded from comparisons between two species and among lettuce types, respectively. These comparisons were not done in the San Joaquin and Santa Maria Valleys because of the small number of fields surveyed in these two valleys.

According to the latitude and longitude measured at each field, a point-coverage was generated for all these fields in geographic information system (GIS) as described previously $(37,39)$. Incidence of lettuce drop, species, and MCGs of the pathogen in each field were mapped in the three valleys.

Within the Salinas Valley, the latitudes and longitudes of the surveyed fields first were transformed into the Universal Transverse Mercator (UTM) coordinates by using the UTM projection in GIS. The UTM coordinates and associated data of lettuce drop incidence then were input into Variowin (25) for geostatistical analysis, and a standardized semivariogram was generated to explore the spatial dependency among the surveyed fields. The same analysis was performed on three data sets: data from October 1999, including 66 fields in a relatively small area; data from spring 2000, including 251 fields throughout the whole Salinas Valley; and the combined data set. Spatial distribution of lettuce drop was not analyzed in the San Joaquin and Santa Maria Valleys because the numbers of fields surveyed were too few to generate meaningful semivariogram.

The frequency of lettuce fields in each of the four categories (with $S$. minor alone, with $S$. sclerotiorum alone, with both species, and with neither species) was calculated for each valley. Pearson's $\chi^{2}$ test was performed to examine whether the frequency varied significantly among the three valleys. The hypothesis tested was that there was no significant difference among the valleys and the expected frequency of each category was the same in all the valleys, which could be calculated as the overall frequency. Therefore, the expected number of fields in each category in a valley can be calculated as the total number of fields surveyed in the valley times the overall frequency of the corresponding category. Then, number of isolates in each MCG also was summarized for both species in the three valleys. In addition to the number of MCGs, in-species MCG diversity, including Shannon's $H$, Simpson, and Berger-Parker indices $(15,24)$, were determined in each valley for both species. The probability that samples from different valleys (two valleys for $S$. sclerotiorum and three valleys for $S$. minor) came from the same population was estimated with a bootstrap procedure (PAST, version 1.40) (13). In all, 1,000 random pairs of samples, each with the same total number of individuals as in the original sample, were taken from the pooled samples with replacement. The difference of each index was calculated between the two samples and the distribution of the difference was used to estimate the probability that the difference between the two original samples resulted from random sampling error. Within the Salinas Valley, frequency of each of the four most prevalent MCGs of $S$. minor was interpolated using the same inverse distance weight method as described previously $(37,39)$. By considering all of the other 19 MCGs as a single category, the
MCG diversity of $S$. minor was approximately determined by calculating a grid of Shannon's $H$ index (30) based on the interpolated grid of frequency $\left(f_{i}\right)$ for each of the four most prevailing MCGs in GIS. For each cell of the grid, Shannon's $H$ index was calculated approximately by using the following formula:

$$
-\sum_{i=1}^{4}\left[f_{i} \bullet \ln \left(f_{i}\right)\right]-\left(1-\sum_{i=1}^{4} f_{i}\right) \bullet \ln \left(1-\sum_{i=1}^{4} f_{i}\right)
$$

Shannon's $H$ index was underestimated by using this formula; however, the underestimate was limited because these MCGs together accounted for $<10 \%$ of isolates for most grids, and there were only a few MCGs for any particular grid. Along the central line of the valley, the average frequency of each of the four MCGs, the average frequency of all 19 other MCGs together, and Shannon's $H$ then were calculated and plotted against the distance from the north end of the valley. The geographical distribution of MCGs of S. minor was not analyzed in the San Joaquin and Santa Maria Valleys because the number of isolates available was too few to provide meaningful results. Because of the limited number of isolates and large number of infrequent MCGs, the interpolation was not performed on the frequency of MCGs of S. sclerotiorum.

\section{RESULTS}

Lettuce drop incidence and affecting factors. Incidence of lettuce drop was significantly $(P<0.05)$ lower in the San Joaquin Valley than in the Salinas and Santa Maria Valleys, and the difference between the latter two valleys was not statistically significant $(P>0.05)$ (Fig. 1A). Within each valley, lettuce drop incidence varied greatly among different fields. In the San Joaquin Valley, lettuce drop incidence was higher $(P<0.05)$ on the spring crops (average $2.3 \%$ ) than on the fall crops (average $0.23 \%$ ). In contrast, in the Salinas Valley, lettuce drop was slightly (not significantly) higher on the fall crops than on the spring crops. Because the results of geostatistical analyses based on the three data sets were all similar, only the results from spring 2000 are presented. The standardized semivariogram indicated that lettuce drop incidence in different fields, which typically were at least $2 \mathrm{~km}$ from each other, tended to be independent from each other in the Salinas Valley (Fig. 1B). Type of irrigation system significantly affected incidence of lettuce drop in the surveyed fields in the Salinas Valley. Fields with surface drip had the lowest drop incidence, significantly $(P<0.05)$ lower than fields with furrow or sprinkler irrigation (Fig. 1C). Lettuce drop incidence also was related to the type of lettuce and growth stage of the lettuce crop. Leaf lettuce had significantly $(P<0.05)$ lower drop incidence than crisphead and romaine lettuce types, while butterhead lettuce was not included for comparison due to the small number of fields with this type of lettuce (Fig. 2). Lettuce drop incidence increased linearly with the growth stage when the number of leaves was used as an indicator of growth stage (data not shown). Drop incidence was significantly $(P<0.05)$ lower in fields infested with $S$. sclerotiorum alone than in fields with $S$. minor alone (Fig. 3).

Geographical distribution of the two Sclerotinia spp. Results from Pearson's $\chi^{2}$ test indicated that the number of fields within each of the four categories differed significantly $\left(\chi^{2}=117.4\right.$, $\mathrm{df}=$ $6, P<0.0001)$ among the three valleys (Table 1$)$. Compared with the expected numbers, there were more fields infested with $S$. minor alone and fewer fields with $S$. sclerotiorum alone in the Salinas Valley, in contrast to more fields with S. sclerotiorum alone and fewer fields with $S$. minor alone in the San Joaquin Valley and more fields with both species in the Santa Maria Valley. All those contributed considerably to the high $\chi^{2}$ value (Table 1). Although deviations from expected frequencies in the Salinas Valley were much smaller than in the San Joaquin Valley, they were large enough to make $\chi^{2}$ tests significant even without 
the contributions from the San Joaquin Valley. In the San Joaquin Valley, most commercial lettuce fields were infested by S. sclerotiorum alone $(49.2 \%)$ or both species $(14.3 \%)$, and very few fields $(11.1 \%)$ by $S$. minor alone. In contrast, most lettuce fields $(68.9 \%)$ were infested by $S$. minor alone in the Salinas Valley

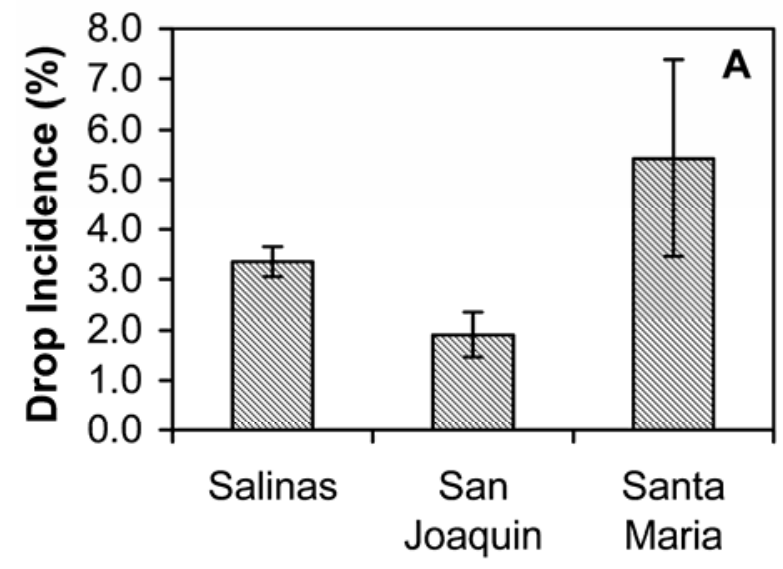

Valleys in central California
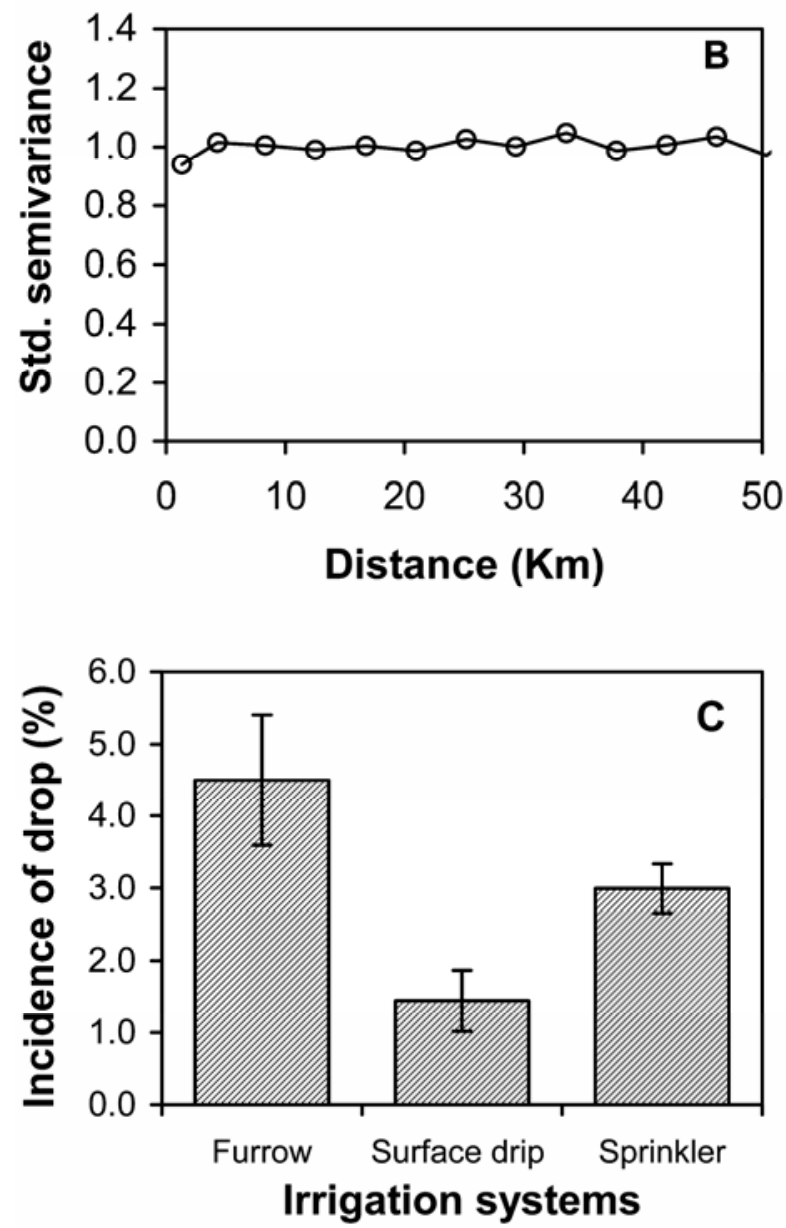

Fig. 1. Analyses of lettuce drop incidence. A, Comparison among the three valleys of central California. Averages and standard errors were calculated from disease incidence in 320, 63, and 37 fields in the Salinas Valley, San Joaquin Valley, and Santa Maria Valley, respectively. B, Spatial dependence among lettuce fields in the Salinas Valley. Analysis was done on data from surveys in 251 fields in 2000. C, Comparison among different irrigation systems in the Salinas Valley. Averages and standard errors were calculated from disease incidence in 72, 17, and 139 fields with furrow, surface drip, and sprinkler irrigation, respectively.
(Table 1). Although $S$. sclerotiorum was observed in a few lettuce fields in the Salinas Valley $(6.4 \%$ by itself and $7.2 \%$ along with $S$. minor), the number of lettuce plants infected by $S$. sclerotiorum was low in these fields. Generally, S. sclerotiorum was observed more frequently in the middle and southern part compared with the northern part of the valley. In the Santa Maria Valley, both species were common, with $S$. minor $(41.7 \%$ by itself plus another $19.4 \%$ where the two species coexisted) slightly more common than $S$. sclerotiorum $(16.7 \%$ by itself plus $19.4 \%$ where the two species coexisted). The percentage of fields without lettuce drop was lowest in the Salinas Valley (17.5\%) and highest in the San Joaquin Valley (25.4\%), with the Santa Maria Valley in between $(22.2 \%)$ (Table 1$)$.

MCGs of the two Sclerotinia spp. In all, 23 different MCGs were identified within $S$. minor; however, $91.4 \%$ of total isolates belonged to 4 MCGs, with other MCGs consisting of one or two

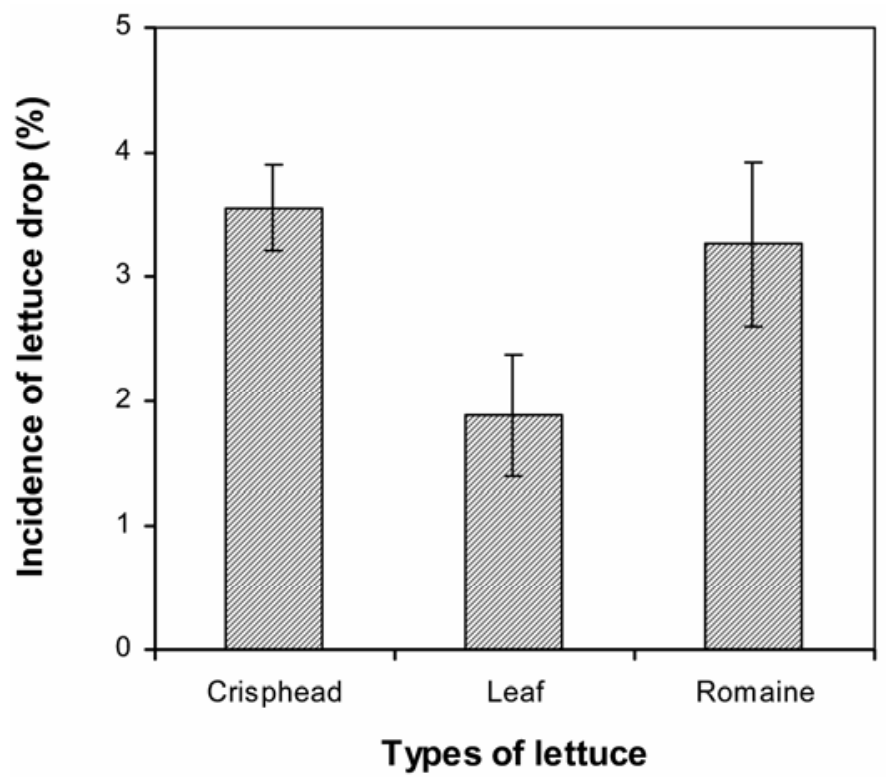

Fig. 2. Incidence of lettuce drop in fields with crisphead, leaf, and romaine lettuce types in the Salinas Valley. Averages and standard errors were calculated from disease incidence in 186, 25, and 100 fields, respectively.

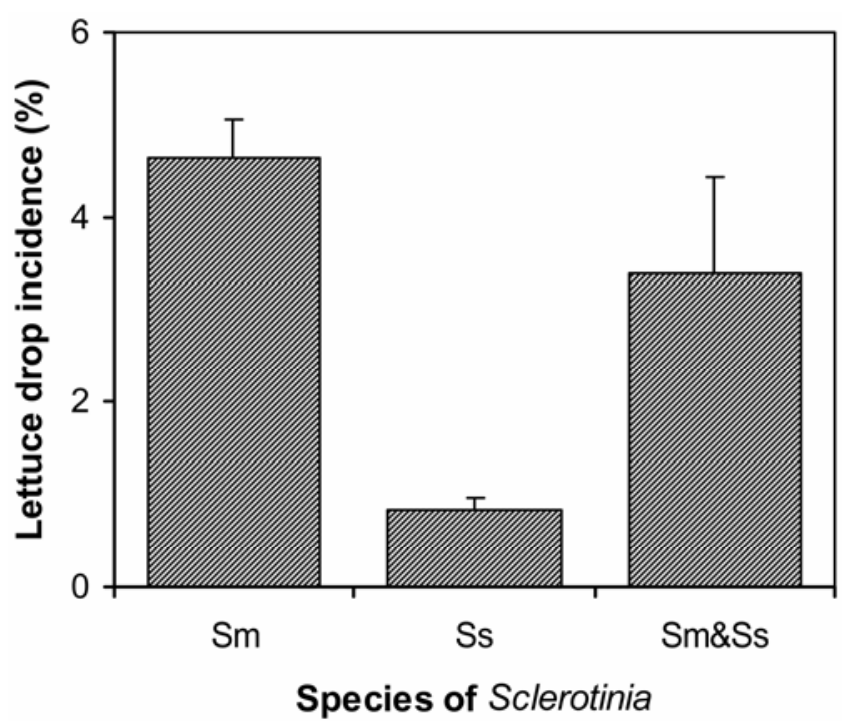

Fig. 3. Incidence of lettuce drop in fields infested with Sclerotinia minor alone (Sm), S. sclerotiorum alone (Ss), and both species (Sm\&Ss) in the Salinas Valley. Averages and standard errors were calculated from disease incidence in 212,22 , and 20 fields, respectively. 
isolates each (Table 2). The isolates of $S$. minor were most diverse with respect to MCG in the Salinas Valley and highly homogeneous in the other two valleys, with almost all isolates belonging to a single MCG. Bootstrapping results indicated that MCG diversity, as measured by number of MCGs, Shannon's $H$ index, Simpson index, and Berger-Parker index, differed significantly $(P<0.001)$ between the Santa Maria and Salinas Valleys, differed significantly $(P<0.05)$ for the last three indices between the Santa Maria and San Joaquin Valleys, and differed significantly $(P<0.05)$ only in Berger-Parker index between the Salinas and San Joaquin Valleys (Table 2). MCG-1 was the most common MCG in all three valleys and accounted for $49.8 \%$ of total isolates. In all, 91 of 208 isolates from the Salinas Valley, 21 of 22 isolates from the Santa Maria Valley, and 9 of 13 isolates from the San Joaquin Valley belonged to MCG-1 (Table 2). Isolates of MCG-2 (25.9\%) and MCG-3 (11.1\%) were limited to the Salinas Valley alone, and isolates of MCG-4 (4.5\%) occurred mainly in the Salinas Valley, with one isolate coming from the San Joaquin Valley (Table 2). Within the Salinas Valley, the interpolated frequency of MCG-1 remained high from north to south (Fig. 4), frequencies of MCG-2 and MCG-3 decreased from north to south (Fig. 4), and the frequency of MCG-4 was very low in the northern end and increased toward the south. The frequency of all the other MCGs together was very low, usually $<5 \%$ (Fig. 4).

The MCG diversity of $S$. minor, measured by Shannon's $H$ index, exhibited substantial geographical variations in the Salinas Valley, greater along the direction of the valley than across the valley (Fig. 5A). The area around Soledad had the lowest diversity, and the highest diversity occurred between Greenfield and King City. Plotting the diversity against the distance from the northern end of the valley revealed that the middle part of the valley had the lowest diversity index and the southern part had the highest (Fig. 5B).

Unlike $S$. minor, MCGs were very diverse among isolates of $S$. sclerotiorum in both the Salinas and San Joaquin Valleys (Table 3 ). Among the 89 isolates collected from the two valleys, 37 different MCGs were identified. The most frequent MCG contained only 16 isolates, all other MCGs contained no more than 7 iso-

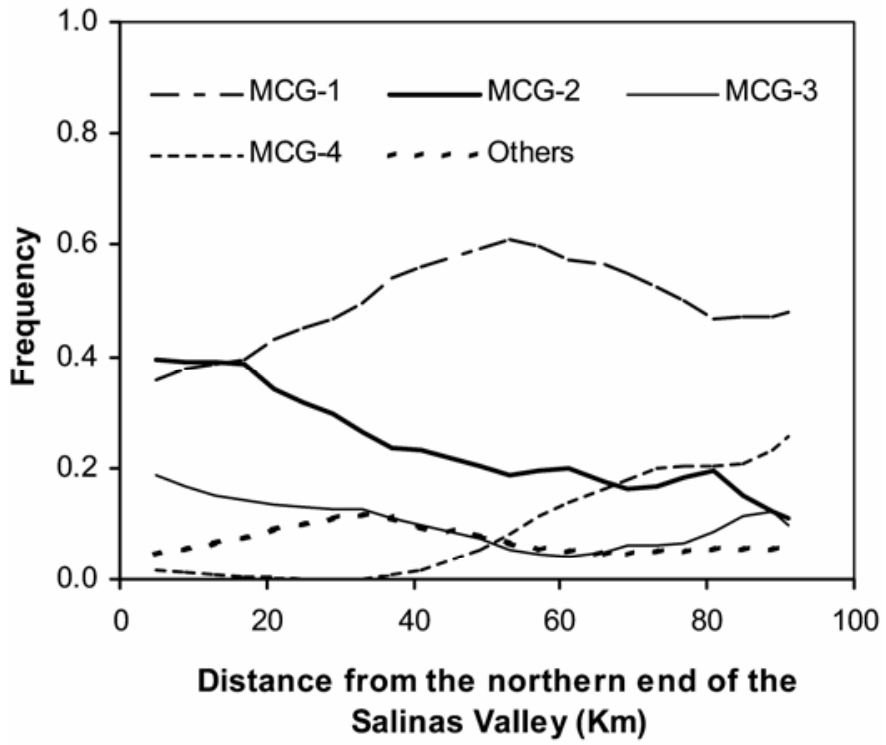

Fig. 4. Frequency of different mycelial compatibility groups (MCGs) along the Salinas Valley, CA.

TABLE 1. Pearson's $\chi^{2}$ test of independence for fields infested with or without Sclerotinia sclerotiorum, S. minor, or both in the Salinas, San Joaquin, and Santa Maria Valleys during 1999 to $2001^{\mathrm{a}}$

\begin{tabular}{|c|c|c|c|c|}
\hline Fields infested with & Salinas & San Joaquin & Santa Maria & Total \\
\hline S. minor alone & $248 / 212(6.2)$ & $7 / 37(24.4)$ & $15 / 21(1.8)$ & 270 \\
\hline S. sclerotiorum alone & $23 / 47(12.3)$ & $31 / 8(62.9)$ & $6 / 5(0.4)$ & 60 \\
\hline Total & 360 & 63 & 36 & 459 \\
\hline
\end{tabular}

a Observed number of fields/expected number of fields (contribution to $\chi^{2}=$ squared difference divided by expected number of fields); $\chi^{2}=117.4$, df $=6$, and $P<0.0001$.

TABLE 2. Isolates of Sclerotinia minor in different mycelial compatibility groups (MCGs), collected from the Salinas, San Joaquin, and Santa Maria Valleys during 1999 to 2001

\begin{tabular}{|c|c|c|c|c|c|c|}
\hline \multirow[b]{2}{*}{ MCGs } & \multirow[b]{2}{*}{ Salinas } & \multirow[b]{2}{*}{ San Joaquin } & \multirow[b]{2}{*}{ Santa Maria } & \multicolumn{3}{|c|}{$P^{\mathrm{a}}$} \\
\hline & & & & S-SJ & S-SM & SJ-SM \\
\hline MCG-1 & 91 & 9 & 21 & $\ldots$ & $\ldots$ & $\ldots$ \\
\hline MCG-2 & 63 & 0 & 0 & $\ldots$ & $\ldots$ & $\ldots$ \\
\hline MCG-4 & 10 & 1 & 0 & $\ldots$ & $\ldots$ & $\ldots$ \\
\hline MCG-5 & 2 & 0 & 0 & $\ldots$ & $\ldots$ & $\ldots$ \\
\hline MCG-6 & 2 & 0 & 0 & $\ldots$ & $\ldots$ & $\ldots$ \\
\hline MCG23 & 0 & 0 & 1 & $\ldots$ & $\ldots$ & $\ldots$ \\
\hline Total isolates & 208 & 13 & 22 & $\ldots$ & $\ldots$ & $\ldots$ \\
\hline Total MCGs & 19 & 5 & 2 & 0.128 & 0.000 & 0.113 \\
\hline Shannon's $H^{\mathrm{b}}$ & 1.557 & 1.044 & 0.185 & 0.232 & 0.000 & 0.020 \\
\hline Simpson index ${ }^{c}$ & 0.697 & 0.497 & 0.087 & 0.061 & 0.000 & 0.024 \\
\hline Berger-Parker ${ }^{\mathrm{d}}$ & 0.438 & 0.692 & 0.955 & 0.033 & 0.000 & 0.039 \\
\hline
\end{tabular}

a Probability estimated with a bootstrap procedure: 1,000 random pairs of samples, each with the same total number of individuals as in the original sample, are taken from the pooled samples with replacement. A small $P$ value indicates a significant difference in diversity index between the two valleys.

b Shannon's $H$ index is a diversity index taking into account the number of individuals as well as number of categories. It is calculated as $H=-\Sigma\left[\left(f_{i}\right) \ln \left(f_{i}\right)\right]$ where $f_{i}$ is the frequency of isolates in the $i$ th MCG.

${ }^{\mathrm{c}}$ Simpson index $=1-$ dominance $=1-\Sigma\left[\left(f_{i}\right)^{2}\right]$ where $f_{i}$ is the frequency of isolates in the $i$ th MCG.

${ }^{\mathrm{d}}$ Berger-Parker dominance is simply the number of isolates in the dominant MCG relative to the total number of isolates; $\mathrm{S}=\mathrm{Salinas,} \mathrm{SJ}=\mathrm{San}$ Joaquin, and $\mathrm{SM}=$ Santa Maria. 
lates, and 30 MCGs contained only one isolate each (Table 3). The MCGs in S. sclerotiorum also differed in geographical distribution. Bootstrapping results indicated that MCG diversity in the species of $S$. sclerotiorum, as measured by Shannon's $H$ index, Simpson index, and Berger-Parker index, differed significantly $(P<0.01)$ between the Salinas Valley and San Joaquin Valley, although the difference in the number of MCGs was not statistically significant $(P=0.051)$ (Table 3$)$. There were many MCGs that were identified within one or a part of the two valleys. For example, the most frequent MCG-A was present only in the northern part of the Salinas Valley, and MCG-M occurred only in the San Joaquin Valley (Table 3).

\section{DISCUSSION}

This study is the first to quantitatively compare the incidence of lettuce drop in commercial production systems at different geo-
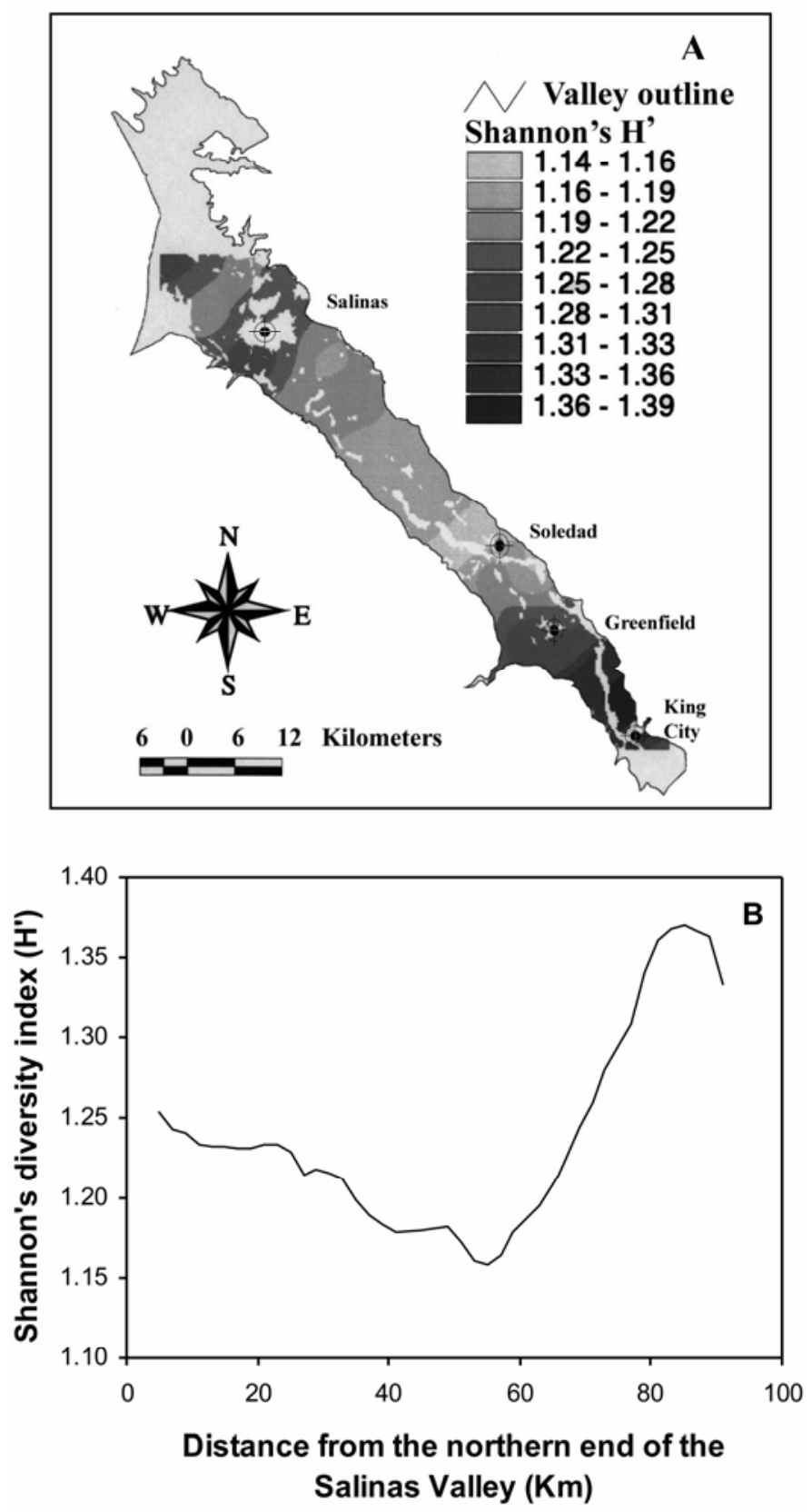

Fig. 5. Shannon's $H$ index calculated based on interpolated frequency of four prevailing MCGs of Sclerotinia minor in the Salinas Valley, CA. A, Spatial grids and $\mathbf{B}$, averages of Shannon's $H$ index along the Salinas Valley. graphical locations. The three valleys of Salinas, San Joaquin, and Santa Maria in central California serve as good examples demonstrating how a combination of weather and lettuce production systems affects the incidence of lettuce drop. In the San Joaquin Valley, the seasonal lettuce production and poor survival (34) between lettuce crops limit the buildup of sclerotia of $S$. minor and lead to low drop incidence caused by this species. Sclerotia of $S$. sclerotiorum infect lettuce mainly by carpogenic germination that requires prolonged periods of high soil moisture (38), but conditions during lettuce production over the course of this study generally were not suitable for carpogenic germination by $S$. sclerotiorum. Therefore, despite superior survival of sclerotia, lettuce drop caused by $S$. sclerotiorum in the San Joaquin Valley also was limited because of inconsistent carpogenic germination. In the Salinas Valley, lettuce drop caused by $S$. sclerotiorum was negligible because no rainfall occurs from April to November, the period of major lettuce production. The windy conditions during this period help evaporate surface moisture and irrigation events cannot satisfy the conditions required for carpogenic germination by $S$. sclerotiorum. In the Salinas Valley, lettuce drop incidence caused by $S$. minor is the major production problem and generally is higher in the fall than in the spring because of the buildup of soilborne sclerotia between spring and fall crops. Decreases in soilborne sclerotia from fall to the subsequent spring, which probably are caused by the relatively longer period between these two seasons coinciding with the wet weather (35), limit the incidence of lettuce drop during spring. Lettuce drop incidence in the Santa Maria Valley serves as a good intermediate example between the other two valleys. The frequent lettuce production system and the foggy weather cause both species to coexist in fields frequently, although the seasonal trends were not investigated because of the limited number of fields surveyed.

This study also confirmed that method of irrigation is an important factor affecting lettuce drop incidence in commercial fields. Although similar studies have been conducted in experimental plots comparing lettuce drop development in the subsurface drip and furrow irrigation systems $(32,35)$, this study was the first to

TABLE 3. Isolates of Sclerotinia sclerotiorum in different mycelial compatibility groups (MCGs) collected from the Salinas and San Joaquin Valleys during 1999 to 2001

\begin{tabular}{|c|c|c|c|}
\hline MCGs & Salinas & San Joaquin & $P^{\mathrm{a}}$ \\
\hline MCG-A & 16 & 0 & $\ldots$ \\
\hline MCG-B & 6 & 1 & $\ldots$ \\
\hline MCG-C & 0 & 5 & $\ldots$ \\
\hline MCG-D & 3 & 0 & $\ldots$ \\
\hline MCG-E to G & 2 each & 1 each & $\ldots$ \\
\hline MCG-H & 2 & 0 & $\ldots$ \\
\hline MCG-I to L & 1 each & 1 each & $\ldots$ \\
\hline MCG-M to $\mathrm{P}$ & 0 & 2 each & $\ldots$ \\
\hline 12 MCGs & 1 each & 0 & $\ldots$ \\
\hline 19 MCGs & 0 & 1 each & $\ldots$ \\
\hline Total isolates & 49 & 40 & $\ldots$ \\
\hline Total MCGs & 23 & 32 & 0.051 \\
\hline Shannon's $H^{\mathrm{b}}$ & 2.587 & 3.349 & 0.005 \\
\hline Simpson index ${ }^{\mathrm{c}}$ & 0.861 & 0.958 & 0.006 \\
\hline Berger-Parker ${ }^{\mathrm{d}}$ & 0.327 & 0.125 & 0.009 \\
\hline
\end{tabular}

${ }^{a}$ Probability estimated with a bootstrap procedure: 1,000 random pairs of samples, each with the same total number of individuals as in the original sample, are taken from the pooled samples with replacement. A small $P$ value indicates a significant difference in diversity index between the two valleys of Salinas and San Joaquin.

b Shannon's $H$ index is a diversity index taking into account the number of individuals as well as number of categories. It is calculated as $H=$ $\left.-\Sigma\left[\left(f_{i}\right)\right] \ln \left(f_{i}\right)\right]$ where $f_{i}$ is the frequency of isolates in the $i$ th MCG.

${ }^{\mathrm{c}}$ Simpson index $=1-$ dominance $=1-\Sigma\left[\left(f_{i}\right)^{2}\right]$ where $f_{i}$ is the frequency of isolates in the $i$ th MCG.

${ }^{\mathrm{d}}$ Berger-Parker dominance is simply the number of isolates in the dominant MCG relative to the total number of isolates. 
compare the surface drip, one currently widely employed irrigation system, with the traditional sprinkler and furrow irrigation systems. Furthermore, the surveys covered a very large area of commercial lettuce production throughout the Salinas Valley, in contrast to the small-scale experimental plots. The results revealed that lettuce drop incidence was significantly lower in fields with surface drip irrigation than in fields with furrow irrigation, suggesting that surface drip irrigation is a potential tool for the management of lettuce drop.

Extensive screening efforts have identified only partial resistance in lettuce germ plasm, and this resistance has been linked to plant architecture $(11,12)$. Lettuce cultivars or lines with upright growth habits are relatively more resistant than other types of lettuce. During the surveys in this study, leaf lettuce showed significantly lower drop incidence than romaine and crisphead lettuce. This result offers some clues for future resistance screening; but, the reasons for the differential reaction of the different lettuce types, including the role of different growth habits and their effects on the microclimates under the canopy and, hence, potential field resistance, need to be clarified further.

Lettuce drop incidence surveyed in this study was not spatially correlated among different fields. The influence range, if any, was less than the distance between two nearby or adjacent fields surveyed. The difference in lettuce drop incidence between two fields was random and not related to the distance between them. This result was consistent with results from the previous studies at the field scale, in which lettuce drop incidence was aggregated only over a short distance $(8,35)$. This not only suggested that the distance over which soilborne sclerotia of $S$. minor can be disseminated was limited, but also implied that variation in lettuce drop incidence within a relatively small area was determined less by the macroscale weather conditions and more by the production and tillage practices and microclimatic conditions in individual fields.

The results of this study also revealed that S. sclerotiorum is still the dominant species in hot climates, such as in the San Joaquin Valley. Because the sclerotia of this species can survive well even during the hot summers (34) and each sclerotium can produce multiple apothecia and release millions of ascospores per apothecium, lettuce drop caused by $S$. sclerotiorum is dependent more on weather conditions affecting production of apothecia and less on the number of sclerotia in soil. For this reason, under the climatic conditions that favor aerial infections by S. sclerotiorum, short-term rotation or soil treatment can hardly provide an effective control to lettuce drop. Instead, control of the disease may rely mainly on manipulating microclimate to reduce carpogenic germination through water management and other practices, and applying fungicides based on good prediction of ascospore production and release. Although $S$. minor has not become economically important in the San Joaquin Valley thus far, it has been detected in a few fields for many years. Because the fields infested by $S$. minor were distributed all over the lettuce-production area in the San Joaquin Valley, the main reason for $S$. minor not causing significant loss in this region is unlikely to be the shortage of inoculum sources. Field experiments previously conducted to determine survival of sclerotia of $S$. minor revealed that fewer sclerotia of this pathogen survived in the San Joaquin Valley than in the Salinas Valley (34). The low prevalence of $S$. minor in the San Joaquin Valley more likely is due to the long gap between two consecutive lettuce crops and reduced survival of sclerotia, factors that prevent buildup of inoculum in soil. For this reason, consecutive lettuce crops in the same field with a short gap between crops should be avoided in order to prevent $S$. minor from becoming a threat to lettuce production in the San Joaquin Valley. Although $S$. minor can survive better under the cool weather conditions in the Salinas Valley, rotation with nonhost crops may offer a very promising management strategy for lettuce drop caused by $S$. minor (14). This study was the first to demonstrate the occurrence of S. sclerotiorum throughout the Salinas Valley, albeit at a lower frequency than in the other two valleys. Based on our studies on carpogenic germination and observation of apothecia in commercial fields and experimental plots (38), the lettuce-free period during the rainy season (winter) may have contributed significantly to limit the damage caused by this species in the Salinas Valley. If changes in production practices led to high soil moisture during the lettuce crop, then severe epidemics of lettuce drop caused by the airborne phase of this species are fully possible.

Both species exhibited some degree of genetic diversity in the three lettuce-production areas in California. Diversity could be a function of a number of factors, both agronomic and inherent to the biology of the two pathogens. The occurrence of the most prevalent MCG-1 of S. minor in the three lettuce-production areas might be an indication of an exchange of inoculum (sclerotia) between the valleys, given that some production equipment is shared and moved around within these areas. However, the MCG diversity of $S$. minor was much higher in the Salinas Valley than in the other two areas, where most isolates belonged to a single MCG, suggesting that the effects of the propagule movement were limited in this species. Similarly, in S. sclerotiorum, the differing types of MCG indicated that movement of pathogen sclerotia between the Salinas and San Joaquin Valleys was not very frequent. There were quite a few MCGs that were found in only one of the two valleys. For example, the most prevalent MCG-A was present only in the Salinas Valley, not in the San Joaquin Valley.

The lower number of MCGs within $S$. minor than within $S$. sclerotiorum, although a possible result of other factors, may be due to more frequent sexual recombination in S. sclerotiorum populations than in $S$. minor populations. $S$. minor requires a longer period of saturated soil moisture than $S$. sclerotiorum to produce apothecia (36), which may partially explain why production of apothecia by $S$. sclerotiorum has been observed widely in nature and seldom by $S$. minor. However, although apothecia of $S$. minor have not been observed in commercial fields in the Salinas Valley, the significantly higher MCG diversity in the Salinas Valley than in the other two valleys could be an indirect indication for occurrence of sexual recombination in the Salinas Valley but not in the other two areas. Even though other factors that affect mutation rate and reproduction of mutants might have contributed to this difference, it may be worthwhile to dedicate greater efforts to gather evidence for sexual recombination in the $S$. minor population in the Salinas Valley. MCGs of S. minor also exhibited great geographical variation inside the Salinas Valley. As measured by Shannon's $H$ index, the MCG diversity was lowest at the middle and highest near the southern end of the valley. This variation may be related to differences in the cropping systems along the valley, which are least diverse in the middle and most diverse at southern part of the valley. Such a relationship between MCG diversity and crop diversity implies that the MCGs of $S$. minor are selected by host crops and, therefore, exhibit host specificity to some extent. However, this hypothesis requires further investigation. Although $S$. sclerotiorum previously was considered to produce apothecia rarely in the Salinas Valley, during this study, the MCG diversity in the Salinas Valley was not very different from that in the San Joaquin Valley, where production of apothecia is common. If sexual recombination is responsible for the higher MCG diversity of S. sclerotiorum as suggested by other researchers $(3,17)$, the results suggested that it should occur in both valleys at similar frequencies. Recently, this was confirmed indirectly by frequent observation of apothecia in both commercial fields and experimental plots in the Salinas Valley (unpublished data).

In summary, this study revealed that geographical location (weather and production system combined), pathogen species, irrigation system, and lettuce type were the major factors affect- 
ing incidence of lettuce drop; confirmed that spatial dependence of incidence between fields was insignificant; and quantified the geographic distribution of the two Sclerotinia spp. and of the MCGs within each species in the three major lettuce-production areas in central California. This study also raised more questions requiring additional research, such as (i) what are the mechanisms causing the high intraspecific diversity of $S$. minor population in the Salinas Valley, (ii) how variable is the aggressiveness among different $S$. minor isolates, (iii) does the sexual recombination of $S$. minor occur in commercial fields in the Salinas Valley, and (iv) how great is the threat of airborne phase of S. sclerotiorum to lettuce production in the Salinas Valley?

\section{LITERATURE CITED}

1. Abawi, G. S., and Grogan, R. G. 1979. Epidemiology of diseases caused by Sclerotinia species. Phytopathology 69:899-904.

2. Adams, P. B., and Tate, C. 1975. Factors affecting lettuce drop by Sclerotinia sclerotiorum. Plant Dis. Rep. 59:140-143.

3. Atallah, Z. K., Larget, B., Chen, X., and Johnson, D. A. 2004. High genetic diversity, phenotypic uniformity, and evidence of outcrossing in Sclerotinia sclerotiorum in the Columbia basin of Washington state. Phytopathology 94:737-742.

4. Beach, W. S. 1921. The lettuce 'drop' due to Sclerotinia minor. Pa. Agric. Exp. Stn. Bull. 165:16-23.

5. Bernstein, L., and Francois, L. E. 1973. Comparison of drip, furrow and sprinkler irrigation. Soil Sci. 115:73-86.

6. Carpenter, M. A., Frampton, C., and Stewart, A. 1999. Genetic variation in New Zealand populations of the plant pathogen Sclerotinia sclerotiorum. N.Z. J. Crop Hortic. Sci. 27:13-21

7. Cubeta, M. A., Cody, B. R., Kohli, Y., and Kohn, L. M. 1997. Clonality in Sclerotinia sclerotiorum on infected cabbage in eastern North Carolina. Phytopathology 87:1000-1004.

8. Dillard, H. R., and Grogan, R. G. 1985. Relationship between sclerotial spatial pattern and density of Sclerotinia minor and the incidence of lettuce drop. Phytopathology 75:90-94.

9. Durman, S. B., Menendez, A. B., and Godeas, A. M. 2003. Mycelial compatibility groups in Buenos Aires field populations of Sclerotinia sclerotiorum (Sclerotiniaceae). Aust. J. Bot. 51:421-427.

10. Ford, E. J., Miller, R. V., Gray, H., and Sherwood, J. E. 1995. Heterokaryon formation and vegetative compatibility in Sclerotinia sclerotiorum. Mycol. Res. 99:241-247.

11. Grube, R. 2004. Genetic analysis of resistance to lettuce drop caused by Sclerotinia minor. Proc. XXVI Int. Hortic. Congr. Adv. Veg. Breed., International Society for Horticultural Science. J. D. McCreight and E. J. Ryder, eds. Acta Hortic. 637:49-55.

12. Grube, R., and Ryder, E. 2004. Identification of lettuce (Lactuca sativa L.) germplasm with genetic resistance to drop caused by Sclerotinia minor. J. Am. Soc. Hortic. Sci. 129:70-76.

13. Hammer, Ø., Harper, D. A. T., and Ryan, P. D. 2001. PAST: Paleontological statistics software package for education and data analysis. Palaeontol. Electron. 4:1-9.

14. Hao, J. J., Subbarao, K. V., and Koike, S. T. 2003. Effects of broccoli rotation on lettuce drop caused by Sclerotinia minor and on the population density of sclerotia in soil. Plant Dis. 87:159-166.

15. Harper, D. A. T. (ed.) 1999. Numerical Palaeobiology. John Wiley \& Sons, Chichester.

16. Imolehin, E. D., and Grogan, R. G. 1980. Factors affecting survival of sclerotia, and effects of inoculum density, relative position, and distance of sclerotia from the host on infection of lettuce by Sclerotinia minor. Phytopathology 70:1162-1167.
17. Kohli, Y., and Kohn, L. M. 1998. Random association among alleles in clonal populations of Sclerotinia sclerotiorum. Fungal Genet. Biol. 23:139-149.

18. Kohli, Y., Morrall, R. A. A., Anderson, J. B., and Kohn, L. M. 1992. Local and trans-Canadian clonal distribution of Sclerotinia sclerotiorum on canola. Phytopathology 82:875-880.

19. Kohn, L. M. 1995. The clonal dynamic in wild and agricultural plantpathogen populations. Can. J. Bot. 73:S1231-1240.

20. Kohn, L. M., Carbone, I., and Anderson, J. B. 1990. Mycelial interaction in Sclerotinia sclerotiorum. Exp. Mycol. 14:255-267.

21. Kohn, L. M., Stasovski, E., Carbone, I., Royer, J., and Anderson, J. B. 1991. Mycelial incompatibility and molecular markers identify geneticvariability in field populations of Sclerotinia sclerotiorum. Phytopathology 81:480-485.

22. Kull, L. S., Pedersen, W. L., Palmquist, D., and Hartman, G. L. 2004. Mycelial compatibility grouping and aggressiveness of Sclerotinia sclerotiorum. Plant Dis. 88:325-332.

23. Melzer, M. S., and Boland, G. J. 1996. Transmissible hypovirulence in Sclerotinia minor Can. J. Plant Pathol. 18:19-28.

24. Muller, K., McDermott, J., Wolfe, M., and Limpert, E. 1996. Analysis of diversity in populations of plant pathogens: The barley powdery mildew pathogen across Europe. Eur. J. Plant Pathol. 102:385-395.

25. Pannatier, Y. 1996. VARIOWIN: Software for Spatial Data Analysis in 2D. Springer-Verlag, New York.

26. Patterson, C. L., and Grogan, R. G. 1985. Differences in epidemiology and control of lettuce drop caused by Sclerotinia minor and Sclerotinia sclerotiorum. Plant Dis. 69:766-770.

27. Patterson, C. L. 1986. The comparative biology, epidemiology, and control of lettuce drop caused by Sclerotinia minor and S. sclerotiorum, and the genetic analysis of vegetative and sexual compatibility in S. minor. Ph.D. thesis, University of California, Davis.

28. Purdy, L. H. 1979. Sclerotinia sclerotiorum: History, disease and symptomatology, host range, geographic distribution and impact. Phytopathology 69:875-880.

29. Ryder, E. J. 1999. Lettuce, Endive, and Chicory. Crop Production in Horticulture Series, Vol. 7. CAB International, Cambridge.

30. Shannon, C. E., and Weaver, W. 1963. The Mathematical Theory of Communication. University Illinois Press, Urbana.

31. Subbarao, K. V. 1998. Progress toward integrated management of lettuce drop. Plant Dis. 82:1068-1078.

32. Subbarao, K. V., Hubbard, J. C., and Schulbach, K. F. 1997. Comparison of lettuce disease and yield under subsurface drip and furrow irrigation. Phytopathology 87:877-883.

33. Wu, B. M., and Subbarao, K. V. 2001. Mycelial compatibility grouping of Sclerotinia minor populations from lettuce in central California. (Abstr.) Phytopathology 91(suppl.):S96.

34. Wu, B. M., and Subbarao, K. V. 2002. Sclerotial survival of S. minor and S. sclerotiorum in California. (Abstr.) Phytopathology 92(suppl.):S88.

35. Wu, B. M., and Subbarao, K. V. 2003. Effects of irrigation and tillage on the dynamics of Sclerotinia minor sclerotia and lettuce drop incidence. Phytopathology 93:1572-1580.

36. Wu, B. M., and Subbarao, K. V. 2005. Comparative studies on carpogenic germination of Sclerotinia sclerotiorum and Sclerotinia minor. (Abstr.) Phytopathology 95(suppl.):S113.

37. Wu, B. M., van Bruggen, A. H. C., Subbarao, K. V., and Pennings, G. G. H. 2001. Spatial analysis of lettuce downy mildew using geostatistics and geographic information systems. Phytopathology 91:134-142.

38. Wu, B. M., Bhat, R. G., Kabir, Z., and Subbarao, K. V. 2003. Production of apothecia by Sclerotinia sclerotiorum in the Salinas valley. (Abstr.) Phytopathology 93(suppl.):S131.

39. Wu, B. M., Subbarao, K. V., and van Bruggen, A. H. C. 2005. Analyses of the relationships between lettuce downy mildew and weather variables using geographic information system techniques. Plant Dis. 89:90-96. 